\title{
Pharmacotherapy for Gastroparesis: An Attempt to Evaluate a Safer Alternative
}

\author{
Uday C Ghoshal, MD, DNB, DM, FACG \\ Department of Gastroenterology, Sanjay Gandhi Postgraduate Institute of Medical Sciences, Lucknow, India
}

\section{Article: Advantages of azithromycin over erythromycin in improving the gastric emptying half-time in adult patients with gastroparesis \\ (J Neurogastroenterol Motil 2010;16:407-413)}

Gastroparesis is a syndrome characterized by symptomatic impairment of transit of foods from stomach to the duodenum in absence of mechanical obstruction. ${ }^{1}$ Though gastroparesis is thought to be an uncommon disorder, many patients with this disease are diagnosed and managed as dyspepsia; ${ }^{2}$ hence, this condition is likely to be under-diagnosed. Gastroparesis may be caused by diabetes mellitus, systemic viral infection, ${ }^{3}$ hypo and hyperthyroidism, hypo and hyperparathyroidism, Addison's disease, collagen vascular diseases, amyloidosis, malignancies, ${ }^{4,5}$ gastric surgery, parkinsonism, other neurodegenerative diseases and myopathies. ${ }^{1}$ In a proportion of patients with gastroparesis, no etiology can be found. Gastroparesis affects about 20\%-30\% of the patients with diabetes mellitus, ${ }^{6}$ which is common and is increasing all over the world. Symptoms of gastroparesis include nausea, vomiting, early satiety, postprandial bloating and abdominal pain. ${ }^{1,7}$ In a series of 146 patients with gastroparesis, frequency of nausea, vomiting, abdominal bloating and early satiety was reported by $92 \%, 84 \%, 75 \%$ and $60 \%$, respectively. ${ }^{7}$ The major goals while treating a patient with gastroparesis include, (1) relieving symptoms particularly vomiting, (2) maintenance of nu- trition and (3) finding and treating the cause, which may be the only potential curative treatment.

Diet that prolongs gastric emptying should be avoided. These include diet rich in fat and fiber. ${ }^{8}$ If patient is on drugs that may prolong gastric emptying, such drugs should be stopped. Though solid emptying from the stomach is prolonged in patients with gastroparesis, liquid emptying is either normal or faster in most. Hence, diet should be liquid or semisolid. Small frequent meals may help the patients. Prokinetics are the mainstay in treatment of gastroparesis. These include metoclopramide, domperidone, itopride, levosulpiride, cintapride, mosapride, tegaserod and macrolide antibiotics such as erythromycin. ${ }^{8,9}$ In refractory patients, prokinetics with different mechanism of action may be combined. In patients refractory to drug treatment, endoscopic intra-pyloric injection of botulinum toxin may be useful. ${ }^{10}$ Gastric pacemaker is useful in refractory gastroparesis. ${ }^{11}$ Surgery is reserved as a last resort in treatment of gastroparesis. ${ }^{12}$ If modified diet can not be tolerated by the patients, parenteral nutrition may be required. ${ }^{12}$ If a specific cause, such as diabetes mellitus or hypothyroidism is detected, treatment directed against this cause

Received: October 1, 2010 Revised: October 5, 2010 Accepted: October 7, 2010

(c) This is an Open Access article distributed under the terms of the Creative Commons Attribution Non-Commercial License (http://creativecommons. org/licenses/by-nc/3.0) which permits unrestricted non-commercial use, distribution, and reproduction in any medium, provided the original work is properly cited.

*Correspondence: Uday C Ghoshal, MD, DNB, DM, FACG

Department of Gastroenterology, Sanjay Gandhi Postgraduate Institute of Medical Sciences, Raebareli Road, Lucknow 226014, India

Tel: +91-962-884-2456, Fax: +91-522-266-8017 (or 8078),E-mail: udayghoshal@gmail.com

Financial support: None.

Conflicts of interest: None. 
may lead to recovery from gastroparesis.

Among the prokinetics, which are the first-line treatment of gastroparesis, cisapride has been withdrawn from the market due to its potential for causing QT prolongation and cardiac arrhythmias. ${ }^{13}$ The pro-motilin macrolide antibiotic erythromycin, accelerates gastric emptying by inducing antral contractions and improved gastroduodenal coordination. ${ }^{14}$ It is quite popular in treatment of gastroparesis in United States of America. However, like cisapride, it has cardiac side-effect such as QT prolongation and may result in potentially fatal cardiac arrhythmias. ${ }^{15}$ Furthermore, gastrointestinal side effects such as nausea and diarrhea are common with erythromycin. ${ }^{16}$ Erythromycin has limitations due to its marked ability to inhibit cytochrome P450 resulting in interaction with drugs, which are metabolized by this enzyme system such as warfarin, carbamazepine and theophylline etc. ${ }^{16}$ Concern about development of microbial resistance to this antibiotic following its use as pro-motility agent is also a growing issue. Hence, attempt to evaluate a safer alternative to erythromycin in treatment of gastroparesis is welcome.

In this issue of the journal, Moshiree et al evaluated whether azithromycin can serve as a safer alternative to erythromycin to promote gastric emptying in patients with gastroparesis. The same group of authors in an earlier study on 30 patients with gastroparesis showed that intravenous erythromycin $250 \mathrm{mg}$ and azithromycin at similar doses showed a similar positive effect on antral activity. However, comparison of erythromycin and azithromycin at the higher dose of $500 \mathrm{mg}$ showed that the mean amplitude, duration of antral activity and motility index were significantly higher with azithromycin. ${ }^{17}$ Recently, another group of workers reported a patient with refractory diabetic gastroparesis responding to high dose $(500 \mathrm{mg} /$ day $)$ intravenous azithromycin. ${ }^{18}$ The present study found that gastric emptying was equally hastened by azithromycin and erythromycin. Both the drugs were found safe during the study period. Hence, authors concluded that azithromycin was equivalent to erythromycin in accelerating gastric emptying in adult patients with gastroparesis. They suggested that longer duration of action, better side effect profile, and lack of P450 interaction of azithromycin as compared with erythromycin may favor azithromycin over erythromycin.

Though such conclusions are quite thought-provoking, the authors correctly suggested the need for more studies. In fact, the present study raises more questions than answers. The issues, which can be raised in the present study include small sample size resulting in a possibility of type II statistical error, non-randomized design, lack of a placebo arm and a short observation period.
Gastroparesis is a chronic disease requiring long-term therapy; hence, a study evaluating short-term effect of a parenteral drug for a chronic disease may not be clinically meaningful. The issue of tachyphylaxis during long-term use of the drug also needs to be addressed. The concern of development of microbial resistance to erythromycin remains with azithromycin as well. Though safety was considered to be a major advantage of azithromycin over erythromycin, this could not be substantiated by the data as a single dose of each drug was used and hence, no side effect was reported with either drug. It is important to note that side-effects are not uncommon on long-term use of macrolide antibiotics such as erythromycin or azithromycin; as high as $28 \%$ patients on erythromycin and $9 \%$ on azithromycin experience gastrointestinal side effects such as nausea and diarrhea. ${ }^{16}$ Moreover, it is important to know whether improvement in gastric emptying following azithromycin would translate into improvement in symptoms. In an earlier study, though erythromycin improved gastric emptying, such improvement was not associated with a beneficial effect on meal related symptom severity. ${ }^{19}$

In spite of all the limitations of the study mentioned above, it is an important step to find out a safer alternative to pharmacotherapy of gastroparesis as "A journey of a thousand miles begins with a small step” Lao Tzu, Chinese Founder of Taoism (570$490 \mathrm{BC})$.

\section{References}

1. Parkman HP, Hasler WL, Fisher RS; American Gastroenterological Association. American Gastroenterological Association technical review on the diagnosis and treatment of gastroparesis. Gastroenterology 2004;127:1592-1622.

2. Talley NJ, Seon Choung R. Functional (non-ulcer) dyspepsia and gastroparesis - differentiating these conditions and practical management approaches. Rev Gastroenterol Disord 2009;9:E48-E53.

3. Bityutskiy LP, Soykan I, McCallum RW. Viral gastroparesis: a subgroup of idiopathic gastroparesis - clinical characteristics and longterm outcomes. Am J Gastroenterol 1997;92:1501-1504.

4. Ghoshal UC, Sachdeva S, Sharma A, Gupta D, Misra A. Cholangiocarcinoma presenting with severe gastroparesis and pseudoachalasia. Indian J Gastroenterol 2005;24:167-168.

5. Sachdeva S, Ghoshal UC, Saraswat VA, Das K, Misra A. Gastroduodenal dysmotility in patients with gallbladder carcinoma: frequency of occurrence and clinical importance. Natl Med J India 2006;19: 4-9.

6. Clark DW, Nowak TV. Diabetic gastroparesis. What to do when gastric emptying is delayed. Postgrad Med 1994;95:195-198, 201 204.

7. Soykan I, Sivri B, Sarosiek I, Kiernan B, McCallum RW. Demography, clinical characteristics, psychological and abuse profiles, treat- 
ment, and long-term follow-up of patients with gastroparesis. Dig Dis Sci 1998;43:2398-2404.

8. Rabine JC, Barnett JL. Management of the patient with gastroparesis. J Clin Gastroenterol 2001;32:11-18.

9. Quigley EM. Pharmacotherapy of gastroparesis. Expert Opin Pharmacother 2000;1:881-887.

10. Bromer MQ, Friedenberg F, Miller LS, Fisher RS, Swartz K, Parkman HP. Endoscopic pyloric injection of botulinum toxin A for the treatment of refractory gastroparesis. Gastrointest Endosc 2005; 61:833-839.

11. Tougas G, Huizinga JD. Gastric pacing as a treatment for intractable gastroparesis: shocking news? Gastroenterology 1998;114:598-601.

12. Bortolotti M. Treatment of gastric emptying delay. Minerva Gastroenterol Dietol 2009;5 5:345-377.

13. Evans AJ, Krentz AJ. Should cisapride be avoided in patients with diabetic gastroparesis? J Diabetes Complications 1999;13:314-315.

14. Annese V, Janssens J, Vantrappen G, et al. Erythromycin accelerates gastric emptying by inducing antral contractions and improved gastroduodenal coordination. Gastroenterology 1992;102:823-828.

15. Ray WA, Murray KT, Meredith S, Narasimhulu SS, Hall K, Stein $\mathrm{CM}$. Oral erythromycin and the risk of sudden death from cardiac causes. N Engl J Med 2004;351:1089-1096.

16. Farrington M. Antibacterial drugs. In: Bennett PN, Brown MJ, eds. Clinical pharmacology. 9th ed. New York: Churchill Livingstone 2003:215-235.

17. Moshiree B, McDonald R, Hou W, Toskes PP. Comparison of the effect of azithromycin versus erythromycin on antroduodenal pressure profiles of patients with chronic functional gastrointestinal pain and gastroparesis. Dig Dis Sci 2010;55:675-683.

18. Sutera L, Dominguez LJ, Belvedere M, et al. Azithromycin in an older woman with diabetic gastroparesis. Am J Ther 2008;15:85-88.

19. Arts J, Caenepeel P, Verbeke K, Tack J. Influence of erythromycin on gastric emptying and meal related symptoms in functional dyspepsia with delayed gastric emptying. Gut 2005;54:455-460. 